\title{
Opiate modulation of gastrointestinal motility and the actions of trimebutine
}

\author{
Stephen M COllins, MB,BS, FRCP(UK), FRCPC, EDWIN E DANIEL, PHD
}

SM COLLINS, EE DANIEL. Opiate modulation of gastrointestinal motility and the actions of trimebutime. Can J Gastroenterol 1991;5(5):185-193. Trimebutine is an opiate ligand that interacts with the $\mu, \delta$ and $\kappa$ receptor subclasses with approximately equal affinity. Since opiate receptors are widely distributed in the gut, and because opiate receptor subtypes may be involved in excitatory or inhibitory control mechanisms, trimebutine has an unusual profile of action that cannot be predicted on the basis of experience with other synthetic opiates such as codeine, morphine or loperamide. Trimebutine influences motility throughout the gastrointestinal tract. The effect of trimebutine on the lower esophageal sphincter raises the possibility of a beneficial role in the treatment of gastroesophageal reflex disease. The ability of trimebutine to promote propulsive activity in the fasting and postprandial small intestine offers novel therapeutic approaches to the treatment of motility disorders, including postoperative ileus and pseudo-obstruction. Finally, the effect of the drug on the colon supports the use of trimebutine in irritable bowel syndrome patients who have constipation due to colonic inertia.

Key Words: Gastrointestinal motility, Muscle, Nerve, Opiates, Pharmacology, Receptors, Trimebutine

\section{Opiacés et motilité gastrointestinale - Les effets de la trimébutine}

RESUME: La trimébutine est un ligand opiacé qui agit avec une affinité à peu près égale au niveau des sous-types de récepteurs $\mu, \delta$ et $\kappa$. Parce que les récepteurs opiacés abondent dans l'intestin et parce que les sous-types de récepteurs opiacés participent peut-être aux mécanismes de régulation excitateurs et inhibiteurs, la

Intestinal Diseases Research Unit and Smooth Muscle Research Program, Departments of Medicine and Biomedical Sciences, McMaster University Medical Centre, Hamilton, Ontario

Correspondence and reprints: Dr SM Collins, Room 3N5c, Intestinal Diseases Research Unit, McMaster Medical Centre, Hamilton, Ontario L8N 325. Telephone (416) 525-9140 ext 2586

Received for publication February 25, 1991. Accepted August 15, 1991
T RIMEBUTINE (2-DIMETHYLAMINO-2phenylbutyl - trimethoxybenzoate maleate; Modulon, Jouveinal) has been used to treat several manifestations of functional bowel disease, including idiopathic (nonulcer) dyspepsia (1), abdominal pain (2) and altered bowel habits (3). The therapeutic benefit of trimebutine in these disorders is believed to be due to its effect on motility (4).

The mechanism of action of trimebutine has only recently become understood. In 1987 in vitro studies provided definitive evidence that trimebutine interacts with opiate receptors in the brain and myenteric plexus $(5,6)$, and it is reasonable to assume that many of the actions of trimebutine on motility are mediated by opiate receptors. In order to understand the effects of trimebutine on motility, it is first necessary to review briefly opiate receptor pharmacology, as well as some principles that underlie the control of gastrointestinal motility.

\section{OPIATE RECEPTORS AND MOTILITY}

Classification of opiate receptors: Naturally occurring opiate peptides are widely distributed in the brain, autonomic nervous system and gut, and in- 
trimébutine présente un mécanisme d'action qu'on ne peut prévoir d'après l'expérience qu'on a des autres opiacés synthétiques tels que la codéine, la morphine et la lopéramide. La trimébutine renforce la motilité des voies digestives. Son effet sur le sphincter oesophagien inférieur laisse entrevoir un rôle bénéfique dans le traitement du reflux gastro-oesophagien. Le fait que la trimébutine stimule la motricité du grêle à jeun et après les repas offre de nouvelles possibilités dans le traitement des troubles de la motilité - iléus post-opératoire et pseudo-obstruction, entre autres. Finalement, l'action du médicament sur le côlon encourage à prescrire la trimébutine aux patients souffrant du syndrome du côlon irritable et de constipation atone.

\section{TABLE 1}

The binding of ligands to opiate receptors in guinea pig brain and myenteric plexus

\begin{tabular}{lccc}
\hline Brain & DHM $(\mu)$ & DADLE $(\delta)$ & EKC $(\kappa)$ \\
\hline Trimebutine & $212 \pm 40$ & $1747 \pm 245$ & $1455 \pm 120$ \\
Dimethyl-trimebutine & $345 \pm 90$ & $1080 \pm 330$ & $1372 \pm 157$ \\
Morphine & $7 \pm 1$ & $152 \pm 52$ & $128 \pm 15$ \\
DADLE & $8 \pm 1$ & $1 \pm 0$ & $2187 \pm 688$ \\
EKC & $1 \pm 0$ & $4 \pm 1$ & $0.5 \pm 0$ \\
\hline Myenteric plexus & DAGO $(\mu)$ & DSLET $(\delta)$ & EKC $(\kappa)$ \\
\hline Trimebutine & $1609 \pm 389$ & $1193 \pm 304$ & $1803 \pm 378$ \\
Dimethyl-trimebutine & $1924 \pm 708$ & $2196 \pm 228$ & $6152 \pm 1183$ \\
Morphine & $7 \pm 1$ & $578 \pm 178$ & $330 \pm 39$ \\
DSLET & $347 \pm 86$ & $23 \pm 7$ & $885 \pm 176$ \\
EKC & - & - & $28 \pm 1$ \\
\hline
\end{tabular}

Shown are the $50 \%$ inhibitory concentration values (in $n M$ ) for the ability of various opiates to displace radioligands from synaptosomes from guinea pig brain or myenteric plexus. The radioligands are shown on the horizontal axis at the top of the table. DADLE (D-Ala $\left.{ }^{2}-D-L e u^{5}\right)$ enkephalin, a $\delta$-selective ligand: DAGQ (D-Ala'-Mephe -Glyof') enkephalin, a $\mu$-selective ligand: DHM Dihydromorphine, a $\mu$-selective ligand: DSLET (D-Ser-L-Leu ${ }^{5}-L-T h r^{\circ}$ ) enkephalin, a $\delta$-selective ligand: EKC Ethylketocyclazocine, a $\mathrm{k}$-selective ligand

\section{TABLE 2}

\section{Differences between trimebutine and morphine}

\begin{tabular}{lll}
\hline Opiate selectivity & Trimebutine $(\mu, \delta, \kappa)$ & Morphine $(\mu)$ \\
\hline Lower esophageal sphincter pressure & Increases & Decreases \\
Normal colonic motility & No effect & Stimulates \\
Colonic transit & Accelerates & Slows \\
Clinical effect & Regulates & Constipates \\
\hline
\end{tabular}

clude met- and leu-enkephalin and dynorphin (7-9). In the gut, these peptides are present in nerves of the myenteric and submucous plexuses $(10,12)$. At least three distinct subclasses of opiate receptors have been identified and are termed $\mu, \delta$ and $\kappa$ receptors on the basis of their affinities for selective opiate ligands. $\mu$ and $\delta$ receptors are usually linked to tissue activation, whereas $\kappa$ receptors are often linked to inhibitory systems. Morphine exhibits selectivity for $\mu$ receptors, whereas trimebutine interacts with $\mu, \delta$ and $\kappa$ receptors with almost equal affinity $(5,6)$ (Tables 1,2). Thus, synthetic opiates may differ substantially in their effects on motility as a result of their profile of selectivity for receptor subclasses.

Sites of action of opiate-induced changes in motility: Opiate receptors that influence gastrointestinal motility are present in the gut as well as in the brain, spinal cord (13) and autonomic ganglia. The ability of centrally administered opiates to affect motility in animals is well recognized.; intracerebroventricu- lar administration of morphine increases myoelectrical spike activity in the feline small intestine (14), and delays intestinal transit in the rat (15). Control is also exerted at the level of the spinal cord and autonomic ganglia; experiments in mice following transsection of the cord have demonstrated the presence of spinal opiate receptors that mediate changes in gastrointestinal motility (16). Opiates also induce changes in nerve cells in autonomic ganglia which receive input from both the brain and periphery, and thus play an important integrative role in the control of gastrointestinal motility (17).

Receptors for opiates within the gut are located primarily on enteric neurons, and opiates influence motility primarily by modulating enteric neural activity. While opiate receptors have been identified on smooth muscle cells isolated from the gut (18), it is uncertain whether they mediate opiate-induced motility responses in vivo. Opiates may also influence motility by altering the hormonal environment in the gut.

Studies in the dog have shown that opiates alter the release of a variety of gut peptides, either via a neural mechanism or by direct stimulation of endocrine cells in the mucosa (19). Of particular importance is the ability of opiates to induce the release of motilin a peptide which induces propagated motor responses in the intestine during the interdigestive state (20). It should be noted that these actions are not mutually exclusive, and that motility response to an opiate observed in vivo may reflect the net effect of several of these mechanisms.

Factors that influence the actions of opiates on motility: In addition to the intrinsic properties of the opiate (ie selectivity for specific receptor subtypes), the effect of an opiate on gastrointestinal motility will be affected by several other factors. These are important not only in the context of therapy, but also in the interpretation of data derived from in vivo and in vitro studies of the mechanisms of actions of opiate ligands.

The state of the gut. The final determinant of gastrointestinal motility is 
the contractile state of smooth muscle in the gut. Enteric nerves contain a variety of neurotransmitters that may ultimately stimulate muscle contraction or induce relaxation, and the net effect of opioids on motor activity will depend on the neurotransmitter content of the nerve. Thus, an opiate-induced increase in motor activity may occur as a result of stimulation of an excitatory nerve or from inhibition of the release of a neurotransmitter that relaxes smooth muscle. An example of this is found in the small intestine of the $\operatorname{dog}(21)$. The administration of opiates, with the exception of dynorphin, results in stimulation of motor activity, presumably via $\mu$ or $\delta$ receptors. The action is blocked by the neuronal blocker tetrodotoxin and reduced by atropine, indicating that part of the effect on motility is due to the activation of cholinergic nerves (21). Since the response was not completely abolished by atropine, a more complex mechanism is suspected. More recent work has shown that motility in the canine small intestine is also under the tonic inhibitory effect of vasoactive intestinal peptide ( $\bigvee I P)$ (a neurotransmitter that relaxes smooth muscle), and that opiates suppress VIP release (22) via both $\mu$ and $\delta$ receptors (unpublished data). Thus, the observed net excitatory effect of opiates in this instance is due to both the activation of excitatory nerves and the suppression of inhibitory nerves.

The converse is also true: opiate-induced suppression of motor activity may result from the inhibition of an excitatory nerve or the activation of an inhibitory nerve (directly or indirectly by withdrawal of inhibitory modulation). The extent to which inhibitory or excitatory effects are seen will depend not only on the intrinsic properties of the opiate but also on whether the intestine is active or quiescent. Effects mediated by inhibitory nerves will only be apparent if the intestine is active, and no effect of the drug will be observed in the unstimulated state.

Presence of gastrointestinal disease. If a disease process alters the function or distribution of enteric nerves, it is reasonable to assume that the motility response to a drug such as an opiate will be altered. It has been shown, for example, that the motor response of the sigmoid colon to exogenous opiate is greatly exaggerated in the presence of active colitis (23). Although the mechanism underlying this observation has yet to be defined, it may reflect alterations in the distribution and content of enteric nerves associated with inflammatory bowel disease $(24,25)$. With respect to functional bowel disease, a similar phenomenon has been observed with colonic motor responses to cholecystokinin (26) and with the gastrocolic reflex (27), which is believed to involve opiate receptors (28). It follows that since a drug may induce quite different responses in healthy subjects than in patients with diseases, then the effects of the drug in patients are not necessarily predictable on the basis of its action in healthy subjects. The point will be illustrated later with trimebutine.

Route of administration of opiate. Because of the wide distribution of opiate receptors that influence motility, the net effect of an administered opiate will also depend on ability to cross the blood brain barrier, the route of administration, and (in the case of in vitro experiments) the structural integrity of the tissue under study. Orally or intravenously administered drugs have access to the brain provided they cross the blood brain barrier. Drugs delivered close to the gut by local intra-arterial injection will primarily act on sites within the gut wall, including intrinsic nerves, muscle, blood vessels and mucosal cells. Drugs applied to muscle strip preparations in vitro will act on intrinsic nerves and muscle. Thus, it is not surprising to observe differences between the responses to central and peripheral administration of opiates and between motility responses to opiates administered in vivo and in vitro (29. 31).

\section{THE MECHANISMS OF ACTION OF TRIMEBUTINE ON MOTILITY}

Overview: Results of radioligand bind. ing studies are consistent with the hypothesis that trimebutine is an opiate ligand that interacts with $\mu, \delta$ and $\kappa$ neural receptors with similar affinity (6). Taken in conjunction with data from physiological studies, these findings are consistent with the notion that trimebutine behaves as a weak nonselective opiate agonist. On the basis of this profile, together with results of in vivo experiments in animals and in humans, the motility profile of trimebutine (and hence its therapeutic potential) cannot be predicted on the basis of familiarity with traditional synthetic opiates such as codeine and morphine. Morphine and codeine are more selective for $\mu$ receptors, whereas trimebutine interacts equally with $\mu, \delta$ and $\kappa$ receptors. Thus, while certain motility effects may be shared (eg, induction of motor complexes in the small intestine), other actions may be quite different (Table 2). From a clinical viewpoint, morphine and codeine slow transit and cause constipation, whereas trimebutine appears to accelerate transit and may therefore be beneficial in the treatment of constipation due to colonic inertia.

Studies on the mechanism and locus of action of trimebutine: In addition to the results of radioligand binding studies described above, there are several studies that describe the mechanisms of action of trimebutine.

Action at extrinsic nerves. The inferior mesenteric ganglion serves to integrate nerve impulses from the central nervous system and peripheral nerves. It connects the central nervous system, the celiac plexus and the gut via the intermesenteric, hypogastric and lumbar colonic nerves, and thus is strategically located to influence gastrointestinal motility. Neurotransmission from preganglionic neurons is cholinergic but is modulated by opiates (17). Studies in the rabbit have shown that trimebutine $(1 \mu \mathrm{g} / \mathrm{mL})$ exerts a bivalent effect on this ganglion, producing either inhibition of cholinergic nerve activity or initial excitation followed by late inhibition, without influencing resting membrane potential (32). Thus trimebutine may influence motility (both initial and long term ex- 

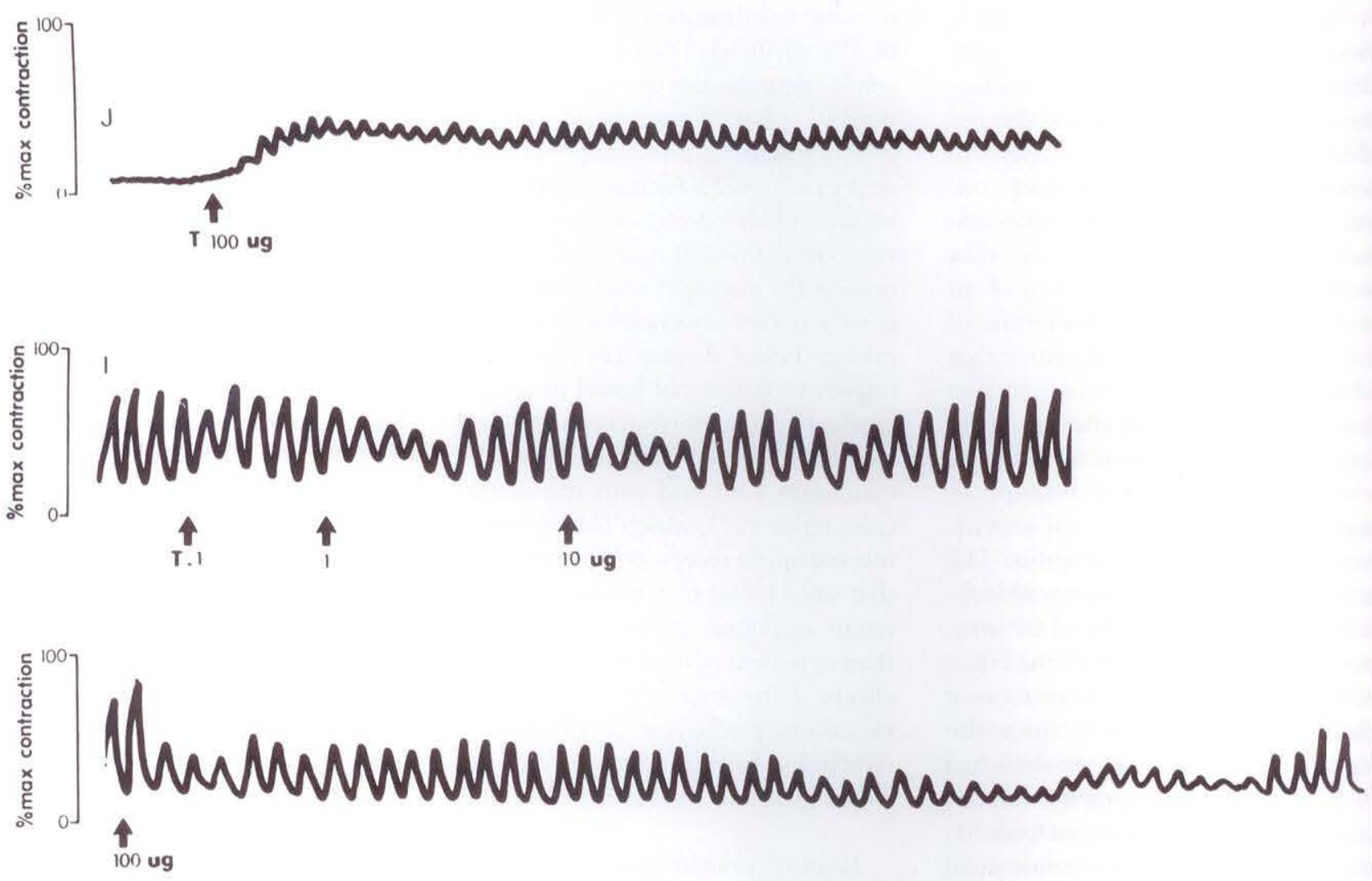

Figure 1) Examples of effects of trimebutine ( $T$ ) on unstimulated (quiet) and field-stimulated intestine. Intra-arterial injections of $T$ are shoun by arrows, and doses are given in $\mu \mathrm{g}$. Top Effects of $T$ on quiet jejunum $(\mathrm{J})$. Note the prolonged submaximal stimulation. Bottom Effects of $T$ on field-stimulated ileum (I). Note the dose-dependent inhibition produced by different doses of $T$ and the prolonged action of higher doses (from reference 34)

citation) by modulating sympathetic tone in the gut by virtue of its action on the inferior mesenteric ganglion.

Local actions of trimebutine in the gut. A recent study investigated the local actions of trimebutine on the gut wall by observing changes in circular muscle contraction following administration of the drug at various sites in the canine gut (33). Trimebutine was given in small boluses by intra-arterial injection in order to restrict its action to the region perfused by the artery. In the stomach, trimebutine, like other opiate agonists, had no excitatory effect in the quiescent gut, but inhibited motility induced by activation of local (post ganglionic) cholinergic nerves. In the quiescent small intestine, trimebutine $(100 \mu \mathrm{g})$ stimulated motility (Figure 1), and the effect was reduced by the neuronal blocker tetrodotoxin or by atropine, and was sensitive to naloxone. These results indicate that part of the trimebutine-induced excitatory effect on motility in the canine small intestine is due to opiate receptor-mediated activation of cholinergic nerves.

The atropine-insensitive component of the above described effect may be due to a direct effect of trimebutine on smooth muscle, to interactions with other nerves (eg, suppression of VIP release [22]), or to the ability of trimebutine to stimulate the release of motilin. When the small intestine was active (following local electrical field stimulation), trimebutine ( 0.1 to 100 $\mu \mathrm{g}$ ) caused inhibition (33) (Figure 1). The effects of trimebutine on the canine stomach and small intestine re- semble those obtained with met-enkephalin under the same experimental conditions, and are thus likely mediated by $\mu$ or $\delta$ opiate receptors $(33,34)$.

The actions of trimebutine in the colon are more complex. Under the experimental conditions described above, trimebutine had no excitatory effect in the canine colon following close intraarterial injection. When the colon was activated, trimebutine caused either weak inhibition or produced no effect at all (33). This profile is similar to that seen with the natural opiates met- or leu-enkephalin or dynorphin under the same conditions. Inhibition of colonic motility was most marked with dynorphin, suggesting that it is mediated primarily by $\kappa$ receptors (34). These findings raise the possibility that the excitatory actions of opiates (including 
trimebutine) on colonic function have their primary sites of action outside the colonic wall.

Peripheral versus central actions of trimebutine. Studies in the dog suggest that the stimulatory effects of trimebutine are mediated via peripheral rather than central opiate receptors (35). The actions of trimebutine were blocked by intravenous but not intracerebroventricular administration of naloxone, and could not be reproduced following intracerebroventricular injection of trimebutine (35).

Effects of trimebutine on the release of gut peptides. It has been shown in the dog that intravenous injection of trimebutine attenuates the postprandial release of several gut peptides (36). Trimebutine $(10 \mathrm{mg} / \mathrm{kg} / \mathrm{h})$ completely inhibited the increase in plasma gastrin, pancreatic polypeptide, insulin, gastric inhibitory peptide and glucagon. Since several of these peptides may influence motility, it is possible that some of the effects of trimebutine on postprandial motility are due, at least in part, to alterations in plasma peptide concentrations. These effects are similar to those observed with leu- and metenkephalin (19).

In contrast to the inhibitory action of trimebutine on the above described peptides, trimebutine causes an increase in the plasma concentration of motilin in the fed or fasted state (37). In the fasted state, the administration of motilin was also associated with the development of a burst of propagated contraction very similar to that seen with phase III of the spontaneous migrating motor complex. Since the latter is also associated with increases in plasma motilin, it has been suggested that endogenous motilin induces the migrating motor complex (38). The subject is controversial, and others claim that the motilin rise is secondary to contractile activity in the intestine (39). Regardless of the causal relationship between endogenous motilin and spontaneous migrating motor complexes, it is possible that motilin contributes to the trimebutine-induced motor responses in the dog, since the observed increase in motilin occurred just before the migrating motor complex.

\section{THE EFFECT OF TRIMEBUTINE ON GASTROINTESTINAL MOTILITY IN HUMANS} Actions on esophageal motility: In healthy fasted subjects, intravenous administration of trimebutine $(50 \mathrm{mg})$ resulted in a twofold increase in lower esophageal sphincter pressure recorded manometrically using the pull-through technique (40). The response lasted approximately 13 mins and was compared to saline injection in a single-blind study of 20 subjects. The effect of trimebutine on lower esophageal sphincter pressure is different from that of morphine which, at intravenous doses of $8 \mathrm{mg}$, decreased sphincter pressure $(41,42)$. Since morphine interacts with $\mu$ receptors, the trimebutine action is likely mediated via $\delta$ receptors, which have been identified in the opossum lower esophageal sphincter (43). Although the effects of trimebutine on the esophageal body have not been described, a met-enkephalin analogue dose-dependently increased the amplitude, duration and propagation velocity of deglutition-induced contractions in humans (44). Taken together, these findings raise the possibility that trimebutine may be beneficial in reducing gastroesophageal reflux. In an uncontrolled study, administration of trimebutine elixir appeared to reduce gastroesophageal reflux in patients with endoscopically proven esophagitis (45). Trimebutine reduced the number and total duration of acid reflux episodes assessed by $\mathrm{pH}$ monitoring during a $3 \mathrm{~h}$ postprandial period in 10 patients. The effect of trimebutine occurred independently of the degree of esophagitis.

Effect on gastric motility and emptying: It is generally accepted that exogenous opiates decrease gastric emptying in animals and in humans (46). In the anesthetized dog, all opiates, including trimebutine, failed to stimulate gastric or pyloric motor activity when administered by close intra-arterial injection, but they universally inhibited motility induced by electrical field stimulation $(33,34)$

In keeping with these data is the observation that trimebutine delays gastric emptying in healthy human sub. jects, illustrated in a placebo controlled, double-blind, crossover study (47). In that study, oral administration of trimebutine $(200 \mathrm{mg}$ ) significantly reduced the gastric emptying of liquid by approximately 19\%. Gastric emptying was measured $1 \mathrm{~h}$ after trimebutine administration by a double sampling method using phenol red dye. The onset of action was $20 \mathrm{mins}$, and the maximum effect of trimebutine was ob. served at 40 mins. The therapeutic value of this effect is unclear, and it may even be detrimental in the application of the drug to treat gastroesophageal reflux.

Actions on small intestine: Several studies have shown that trimebutine affects intestinal motility in both the fasted and postprandial states $(48,49)$. In the fasted state, intravenous administration of trimebutine $(100 \mathrm{mg}$ ) induced aborally propagated motor complexes that resembled the intestinal component of spontaneous phase III interdigestive migrating motor complexes in terms of duration, propagation velocity and frequency of contraction (48). However, unlike spontaneous migrating motor complexes that occur first in the gastric antrum, trimebutineinduced complexes occurred only in the intestine, and antral activity was, in fact, suppressed. This effect of trimebutine was abolished by intravenous infusion of naloxone $(40 \mathrm{mg} / \mathrm{kg} / \mathrm{h})$, and was similar to that induced by administration of morphine (49), indicating the involvement of opiate $\mu$ receptors.

In another study in which intravenous trimebutine $(100 \mathrm{mg})$ produced similar responses, the phase III-like motor complexes differed from spontaneous migrating motor complexes in that they were not accompanied by an increase in plasma motilin (50). Furthermore, others showed that administration of trimebutine suppressed plasma motilin concentrations in fasted healthy subjects, and that this effect was naloxone sensitive (48). These results differ from those reported in the dog, in which trimebutine-induced phase III-like activity was accompanied by an increase in plasma motilin concentration (37). These findings reflect 


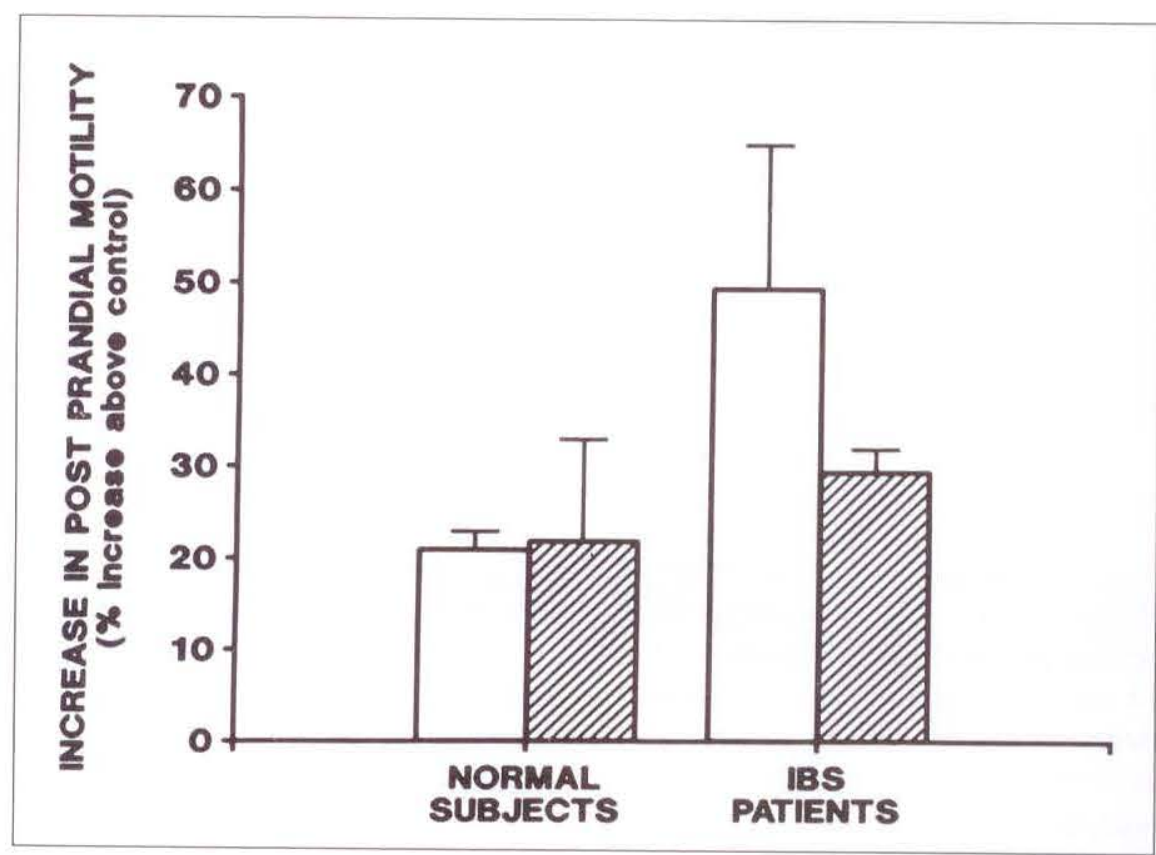

Figure 2) The increases in postprandial colonic motility in the presence or absence of trimebutine in normal subjects and in patients with irritable bowel syndrome. The increase in motility is expressed as the mean percentage of increase above fasting values. Shown is the mean and SEM for each group, based on an analysis of eight normal subjects and seven patients with irritable bowel syndrome. Responses following trimebutine administration are shown by the hatched bars. The figure shows that trimebutine reduces the abnormal increase in postprandial motor activity in irritable bowel syndrome patients but does not affect motor activity in healthy controls (adapted from reference 56)

species שifferences in the control of interdigestive motility by opiates in animals and humans.

In the fed state in humans, intravenous administration of trimebutine (100 mg) 40 mins after a $500 \mathrm{kcal}$ meal interrupted postprandial motor activity with a motor complex that resembled the migrating motor complex of the interdigestive state (50). The action of trimebutine on postprandial intestinal motility may reflect the ability of that drug to prevent the postprandial increase in the hormones gastrin, insulin, gastric inhibitory polypeptide and glucagon, demonstrated recently in the dog (36).

The ability of trimebutine to stimulate propagated motor activity would suggest that the drug may be useful in accelerating transit through the small intestine. This was shown with the duodenal transit of liquid in healthy subjects using a dye dilution technique (51). The effect of trimebutine on small bowel transit may underlie its reported benefit in reducing duodenogastric alkaline reflux. In an open study, tri- mebutine was shown to reduce episodic alkaline reflux in patients with endoscopically proven bile reflux gastritis (52). In this study, gastric $\mathrm{pH}$ was monitored in 12 patients for $24 \mathrm{~h}$ before and after one month of oral trimebutine therapy $(6 \mathrm{mg} / \mathrm{kg} / \mathrm{day})$. Trimebutine had no effect on gastric basal $\mathrm{pH}$ but significantly reduced the mean number and duration of episodes during which the gastric $\mathrm{pH}$ exceeded 4 . This was associated with symptomatic improvement in eight of the 12 patients. Although the results were interpreted in light of an effect of trimebutine on gastroduodenal motility, the extent to which the data were influenced by a direct effect on gastric acid secretion is not known.

The stimulatory effect of trimebutine in the intestine has also been applied to two conditions associated with slow transit in the small bowel: paralytic ileus and pseudo-obstruction. In patients with postoperative ileus, administration of intravenous trimebutine ( 50 to $300 \mathrm{mg}$ ) increased spiking activity in the small intestine, and the response was dose-dependent (53). Infusion of trimebutine for $12 \mathrm{~h}$ per day was also reported to accelerate the onset of the first passage of flatus postoperatively in these patients, from a mean of 70 to $54 \mathrm{~h}$.

In infants with pseudo-obstruction, characterized manometrically by extensive disruption of interdigestive motility in the small bowel, intravenous trimebutine $(3 \mathrm{mg} / \mathrm{kg})$ induced phase III-like motor complexes which were propagated aborally (54). In two of the four patients studied, the administration of trimebutine was accompanied by the passage of flatus and a reduction in abdominal girth.

Actions on the colon: Rectosigmoid motility in normal subjects. In fasted (48) or fed (55) healthy human subjects, neither intravenous nor oral administration of trimebutine $(100 \mathrm{mg}) \mathrm{had}$ an effect on motor activity measured manometrically in the sigmoid colon; this is in keeping with the actions of naturally occurring enkephalins in the $\operatorname{dog}(56)$. These findings again illustrate that trimebutine differs from other synthetic opiates such as morphine, codeine and loperamide, which invariably stimulate motor responses in the rectosigmoid $(57,58)$. Because of regional differences, it should be emphasized that results obtained manometrically in the sigmoid colon may not necessarily reflect those recorded from more proximal regions of the colon. However, the absence of a trimebutine effect elsewhere in the healthy colon is supported by reports of unaltered colonic transit times following trimebutine administration in sub. jects with 'normal' colonic transit (59).

Rectosigmoid motility in patients with irritable bowel syndrome. In a study of irritable bowel syndrome patients, motor activity was recorded mano. metrically before and after a meal $(990$ to $1100 \mathrm{kcal}$ ) and then for 30 mins after the administration of intravenous trimebutine ( $50 \mathrm{mg}$ ) (60). Entry criteria included demonstration of an 'abnormal' colonic motor response to a meal, based on the authors' prior experience with 20 normal subjects. Of 16 irritable bowel syndrome patients entered, seven 
were classified as exhibiting 'hypomotility' with a poor response to meals, and seven were classified into a 'hypermotility' group exhibiting an exaggerated meal response. In irritable bowel syndrome patients with basal 'hypomotility', trimebutine significantly increased the postprandial motor response, whereas in the patients with basal and postprandial 'hypermotility', trimebutine significantly reduced motor activity.

The suggestion of a modulating effect of trimebutine on colonic motor activity was further supported by a recent placebo controlled, crossover study in which rectosigmoid motility was recorded manometrically in nine constipated irritable bowel syndrome patients and 11 normal subjects (55). Trimebutine was administered in a single oral $200 \mathrm{mg}$ dose $20 \mathrm{mins}$ before the ingestion of a meal. Following placebo ingestion, the rectosigmoid motor response to the meal (gastrocolic reflex) was significantly larger in the irritable bowel syndrome group compared to controls (increases over baseline of $49.1 \%$ versus $21.9 \%$ ). Administration of trimebutine attenuated the meal-induced response in the irritable bowel syndrome group (reducing it from 49.1 to $28.9 \%$ ), bringing it into a range closer to that to normals (Figure 2). In contrast, the opposite trend was observed in normal subjects in whom trimebutine caused a small, statistically insignificant increase in the postprandial response (from 21.9 to $23.9 \%$ ). Since this was an acute study, symptoms were not assessed.

Transit studies: In constipated irritable bowel syndrome patients, oral administration of trimebutine ( $200 \mathrm{mg}$ tid) for eight weeks significantly improved abdominal pain and constipation, superior to placebo in a double-blind crossover study (3). These findings were accompanied by a significant decrease in whole gut transit time of radiopaque markers. Since the colon is a major determinant of gut transit, these studies suggest an effect of trimebutine on colonic motility in constipated irritable bowel syndrome patients.

Similar results were obtained in another double-blind, placebo control- led, crossover study in which irritable bowel syndrome patients with abdominal distension, pain and constipation were given trimebutine or placebo for one month, and each treatment was separated by a one week washout period (59). The study group contained 12 patients with slow colonic transit, and 12 patients with normal transit times of less than $40 \mathrm{~h}$, assessed by the passage of radiopaque markers. All patients had failed to improve on fibre supplements prior to entering the study. Trimebutine therapy caused a significant reduction in colonic transit time from $105 \pm 19$ to $60 \pm 11 \mathrm{~h}(\mathrm{P}<0.015)$ in the slow transit group, without a significant change occurring in the group with normal colonic transit times. Symptoms of abdominal distension and pain relieved by defecation were significantly improved in both groups, but there was no change in stool frequency compared to placebo.

Colonic myoelectrical activity: The field of recording and interpreting myoelectrical signals from the human colon in vivo is fraught with difficulties and conflicting data. There is agreement between some groups that myoelectrical activity may be described in terms of long and short spike bursts (61). Short spike bursts last about $3 \mathrm{~s}$, are localized, seldom propagate, and are common in the proximal colon. They serve to retard the fecal stream and prolong transit; they are found in increased numbers in constipated humans (62) and experimentally constipated dogs (63). Long spike bursts last about $21 \mathrm{~s}$, may propagate ad-or aborally, and are found mainly in the distal colon (62).

Placebo controlled studies on the action of trimebutine on colonic myoelectrical activity in irritable bowel syndrome patients have yielded conflicting results. In one study, trimebutine had no effect on short spike bursts in either constipated irritable bowel syndrome patients nor in those with diarrhea (64); trimebutine did reduce the duration of long spike bursts in both subgroups of patients, but the therapeutic significance of this finding is not apparent. However, in another study (59), trimebutine significantly increased the number of propagated spike bursts in patients with constipation. Since this type of activity has been positively correlated with propulsive movement in the colon, the finding is in keeping with the documented effects of trimebutine in accelerating colonic transit in irritable bowel syndrome patients with constipation $(3,59)$.

In an uncontrolled study of the action of trimebutine on rectosigmoid activity in normal subjects and irritable bowel syndrome patients, trimebutine appeared to exhibit a 'normalizing' effect (65). Recordings were taken from the region of the rectosigmoid junction where the authors claimed that spiking activity remains relatively constant at a frequency of 0 to 2 spike bursts/min. In five normal subjects, intravenous trimebutine ( $100 \mathrm{mg}$ ) had no substantial effect on electrical activity, but stimulated spike bursts in one asymptomatic subject who had no discernible basal activity. In seven irritable bowel syndrome patients with increased basal spiking activity, trimebutine appeared to decrease activity. An additional 11 irritable bowel syndrome patients had normal basal spiking activity, and in eight of these, trimebutine had no effect but the drug increased spike bursts in the remaining three patients. Since no information was provided regarding the clinical status of the trimebutine responders and nonresponders, and because the study was uncontrolled, the data are of limited use, although they may provide an example of a bivalent or 'normalizing' effect of trimebutine on human gastrointestinal motility.

Synthesis: In balance, the results of studies on colonic transit, motility and myoelectrical activity are consistent with the view that trimebutine accelerates slow transit in the colon by encouraging propagated motility in the proximal colon and reducing nonpropagated activity in the sigmoid region. The clinical extrapolation of these data is that trimebutine may be useful in treating constipation due to colonic inertia.

\section{REFERENCES}

1. Walters JM, Crean P, McCarthy CF. Trimebutine, a new antispasmodic in the treatment of dyspepsia. Irish Med J 1973;10:380-1. 
2. Luttecke K. A trial of trimebutine in spastic colon. J Int Med Res 1978;6:86-8.

3. Moshal MG, Herron M. A clinical trial of trimebutine (Mebutin) in spastic colon. J Int Med Res 1979;7:2331-4.

4. Pascaud X, Foman F, Petoux F, Vauche D, Junien JL. Action de la trimébutine sur la motricité gastro-intestinale. Gastroenterol Clin Biol 1987;11:77B-81B.

5. Roman F, Pascaud X, Taylor JF, Junien JL. Interactions of trimebutine with guinea pig opioid receptors. J Pharm Pharmacol 1987;39:404-7.

6. Pascaud-X, Roman-F, Petoux-F, Vauche-D, Junien-J-L. Involvement of opiate receptors in the mode of action of trimebutine. Gastroenterol Clin Biol 1987;11:77B-81B.

7. Hughes J, Smith TW, Kosterlitz HW, Fothergill L, Morgan BA, Morris HR. Identification of two related pentapeptides from the brain with potent opiate agonist activity. Nature 1975;258:577-9.

8. Lord JAH, Waterfield AA, Hughes J, Kosterlitz HW. Endogenous opioid peptides: Multiple agonists and receptors. Nature 1977;267:495-9.

9. Sundler F, Bjartell A, Bottcher G, Ekblad E, Hakanson R. Localization of enkephalins and other endogenous opioids in the digestive tract. Gastroenterol Clin Biol 1987,71:14B-26B.

10. Larsson LI, Stenagaard-Pederson K. Immunocytochemical and ultrastructural differentiation between met-enkephalin, leu-enkephalin and met/leu enkephalin immunoreactive neurons of feline gut. J Neurosci 1982:2:861-78.

11. Costa M, Furness JB, Cuello AC. Separate populations of opioid containing neurones in the guinea pig intestine. Neuropeptides 1985:5:445-8.

12. Costa M, Furness JB, Gibbons IL, Murphy R. Chemical coding and projections of opioid peptide containing neurons in the guinea pig intestine. Neurosci Lett 1985;22:S19.55.

13. Burks TF, Galligan JJ, Hirning LD, Porreca F. Brain, spinal cord and peripheral sites of action of enkephalins and other endogenous opioids on gastrointestinal motility. Gastroenterol Clin Biol 1987;11:44B-51B.

14. Stewart JJ, Weisbrodt NW, Burks TF. Centrally mediated intestinal stimulation by morphine. J Pharmacol Exp Ther 1977;202:174-81.

15. Stewart JJ, Weisbrodt NW, Burks TF. Central and peripheral actions of morphine on intestinal transit.
J Pharmacol Exp Ther

1978;205:547-55.

16. Porreca F, Filla A, Burks TF. The spinal cord-mediated opiate effects on gastrointestinal transient mice.

J Pharmacol Exp Ther 1983;227:22-7.

17. Fileccia R, Jule Y. Effects of enkephalins on synaptic transmission in the inferior mesenteric ganglion of the cat. J Physiol (Lond) 1983:345-66.

18. Bitar KN, Makhlouf GL. Selective presence of opiate receptors on intestinal circular muscle cells. Life Sci 1985;37:1545-50.

19. Champion MC, Sullivan SN, Bloom SR, Adrian TE, Christofides NS. The effects of naloxone and morphine on postprandial gastrointestinal hormone secretion. Am J Gastroenterol 1982;77:617-20

20. Poitras P. Motilin is a digestive hormone in the dog. Gastroenterology 1984;87:909-13.

21. Fox JET, Daniel EE. Exogenous opiates: Their local mechanisms of action in the canine small intestine and stomach. Am J Physiol 1987;253:G179-88.

22. Manaka H, Manaka Y, Kostolanska F, Fox JET, Daniel EE. Release of VIP and substance $\mathrm{P}$ from isolated perfused canine ileum. Am J Physiol 1989;257:G182-90.

23. Garrett JM, Sauer WG, Moertel CG. Colonic motility in ulcerative colitis after opiate administration. Gastroenterology 1967;53:93-100.

24. Dvorak AM, Connell AB, Dickersin GR. Crohn's disease, a scanning electron microscopic study. Hum Pathol 1979;10:165-77.

25. Bishop AE, Polack JM, Bryant MG, Bloom SR, Hamilton S. Abnormalities of vasoactive intestinal polypeptide containing nerves in Crohn's disease. Gastroenterology 1980;79:853.

26. Harvey RF, Read AE. Effect of cholecystokinin on colonic motility and symptoms in patients with irritable bowel syndrome. Lancet 1973;i:1-3.

27. Waller S, Misiewicz JJ, Kiley N. Effect of eating on motility of the pelvic colon in constipation and in diarrhoea. Gut 1972;13:805-11.

28. Sun EA, Snape WJ, Cohen S, Renny A. The role of opiate receptors and cholinergic neurons in the gastrocolic response. Gastroenterology 1982;82:689-93.

29. Bueno L, Fioramonti J. Enkephalins, other endogenous opioids and colonic motility in dog and man. Gastroenterol Clin Biol 1987;11:69B-76B.

30. Fioramonti J, Fargeas MJ, Bueno L. Comparative effects of morphine and cyclazocine on gastrointestinal motility in conscious dog. Arch Int
Pharmacodyn Ther 1984;270:141-50.

31. Schulz R, Wuster M, Herz W.

Centrally and peripherally mediated inhibition of intestinal motility by opioids. Neunyn-Schmeibeberg Arch Pharmacol 1979;308:255-64.

32. Jule Y. Effets de la trimébutine sur la transmission cholinergique au niveau des neurones du ganglion mesentérique inférieur du lapin. Gastroenterol Clin Biol 1987;11:83B-5B.

33. Daniel EE, Kostolanska F, Fox JET. Local actions of trimebutine on canine gastrointestinal tract. Gastroenterol Clin Biol 1987;11:86B-8B.

34. Daniel EE, Fox JET, Allescher H-D, Ahmad S, Kostolanska F. Peripheral actions of opiates in canine gastrointestinal tract: Actions on nerves and muscles. Gastroenterol Clin Biol 1987;11:35B-43B.

35. Fioramonti J, Fargeas MJ, Bueno L. The involvement of opiate receptors in the effects of trimebutine on intestinal motility in the conscious dog. J Pharm Pharmacol 1984;36:618-21.

36. Poitras P, Hinde C, Goyer R, Junien JL, Pascaud X, Greenherg GR. Effet de la trimébutine sur la libération plasmatique post-prandiale d'hormones gastro-intestinales chez le chien. Gastroenterol Clin Biol 1987;11:94B-6B.

37. Poitras P, Honde C, Havzankova J, et al. Effects of trimebutine on intestinal motility and plasma motilin in dog. Am J Physiol 1986;251:G349-53.

38. Poitras P, Trudel L. Contrôle par les opiaces endogènes de la motilinémic et du complex moteur migrant chez le chien. Gastroenterol Clin Biol 1987;11:62B-4B.

39. Sarna S, Chey WY, London RE, Dodds WJ, Myers T, Chang TM. Cause-and-effect relationship between motilin and migrating myoelectric complexes. Am J Physiol 1983;245:G277-84.

40. Bel A, Ricord J-L, Penet A, Noun K. The action of intravenous trimebutine on the lower esophageal sphincter of the esophagus of the healthy adult. Gaz Med France 1982;89:2954-7.

41. Hall AW, Moosa AR, Clark J, Cooley GR, Skinner DB. The effects of premedication on the lower esophageal high pressure zone and reflux status of Rhesus monkeys and man. Gut 1975;16:347-52.

42. Mittal RK, Frank EB, Lange RC, McCallum RW. Effects of morphine and naloxone on esophageal motility and gastric emptying in man. Dig Dis Sci 1986; $31: 936-42$.

43. Rattan S, Goyal RK. Identification and localization of opioid receptors in the opossum lower esophageal 
sphincter. J Pharmacol Exp Ther 1983:224:391-7.

44. Stacher G, Bauer P, Steinringer H, Schmiere G, Langer $B, W$ inklehner $S$. Dose related effects of the synthetic met-enkephalin analogue FK 33-824 on esophageal motility in healthy humans. Gastroenterology 1982;83:1057-61.

45. Gosselin A. Effect of Debridat on gastroesophageal reflux as measured by prolonged $\mathrm{pH}$ metry. Gaz Med France 1982;89:22.

46. Dubois A. Endogenous opioids, gastric motility, and gastric emptying. Gastroenterol Clin Biol 1987;11:56B-61B.

47. Suyama T, Miyoshi A, Hori R, Ishimoto M. Studies on the clinical effects of trimebutine (TM906) on gastric emptying time using double sampling method. Jpn Arch Intern Med 1980;27:159-67.

48. Valori R, Shannon S, Reddy N, Daniel EE, Collins SM. The action of trimebutine maleate on gastrointestinal motility is mediated by opiate receptors in human subjects. Gastroenterol Clin Biol 1987;11:102B-4B.

49. Waterfall WE. Electrical patterns in the human jejunum with and without vagotomy: Migrating myoelectrical complexes and the influence of morphiné. Surgery 1983;94:186-9.

50. Chaussade S, Grandjouan S, Couturier D, Thierman-Duffaud D, Henry JF. Effect of trimebutine on proximal small intestinal motility in normal humans. Gastroenterol Clin Biol 1987;11:97B-110B.

51. Schang JC, Muller J, Rico E, Grenier JF. Effets accélérateurs de Debridat (trimebutine) sur le transit duodénal. J Med Strasbourg 1977;8:335-8.

52. Glikmanas M, Souillac P, GatineauSaillant G, Prat B. Effet sur le reflux duodéno-gastroqie de Ca modification de la motricité duodénal induite par la trimébutine. Actualites Ther MCD 1984;13:653-8.

53. Grenier J-F, Schang J-C, Dauchel J. Etude electromyographie des effets de la trimébutine sur la motricité intestinal au cours de la période post opératoire. J Med Strasbourg 1977:5:335-8.

54. Boige N, Cargill G, Mashako L, Cezard JP, Navarro J. Trimebutine-induced phase III like activity in infants with intestinal motility disorders. J Pediatr Gastroenterol 1987;6:548-53.

55. Shannon S, Hollingsworth J, Cook IJ, Collins SM. Effect of trimebutine on postprandial colonic motor activity in healthy subjects and patients with irritable bowel syndrome. J Gastroenterol Motility 1989;1:9-14.

56. Bueno L, Fioramonti J. Honde C, Farageas MJ, Primi MP. Central and peripheral control of gastrointestinal and colonic motility by endogenous opiates in conscious dogs. Gastroenterology 1985;88:549-56.

57. Fioramonti J, Fargeas MJ, Bueno L. Stimulation of gastrointestinal motility by loperamide in dogs. Dig Dis Sci 1987;62:641-6.

58. Ingram DM, Catchpole BN. Effects of opiates on gastroduodenal motility following surgical operation. Dig Dis Sci 1981;26:989-92.

59. Schang JC, Devroede G, Pilote M. Beneficial effects of trimebutine in patients suffering from irritable bowel disease (IBS) with normal transit or constipation. Gastroenterology 1988;94:A403.

60. Meunier P, Lambert R. Effets de la trimébutine sur la motricité colique dans les colopathies. Gastroenterol Clin Biol 1980;4:261 A. (Abst)

61. Bueno L, Fioramonti J, Ruckebusch Y, Frexinos J, Coulon P. Evaluation of colonic myoelectrical activity in health and functional disorders. Gut 1979:21:480-5.

62. Bueno L, Fioramonti J. Patterns of colonic motility. Clin Res Rev 1981;1:91-100.

63. Fioramonti J, Garcia-Villr R, Bueno L, Ruckebusch Y. Colonic myoelectrical activity and propulsion in the dog. Dig Dis Sci 1980;25:641.

64. Frexinos J, Fioramonti J, Bueno L. Effects of trimebutine on colonic myoelectrical activity in irritable bowel syndrome patients. Eur J Clin Pharmacol 1985;28:181-5.

65. Isman H, Lupo B, Nakache R. Effect of 'Debridat' (rrimebutine) on sigmoid and rectosigmoid motility in normal and pathological states. Gaz Med France 1983;89:1272-6. 


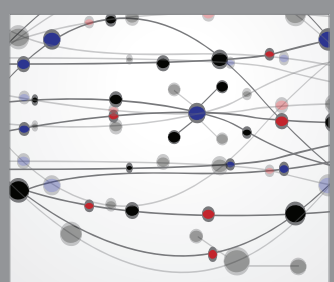

The Scientific World Journal
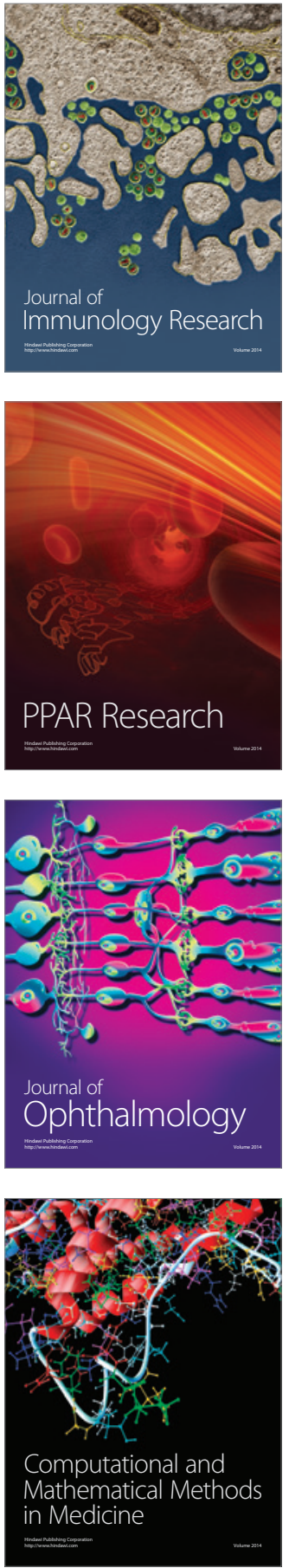

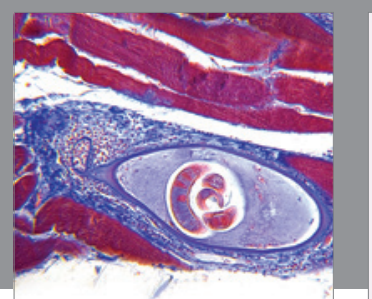

Gastroenterology Research and Practice

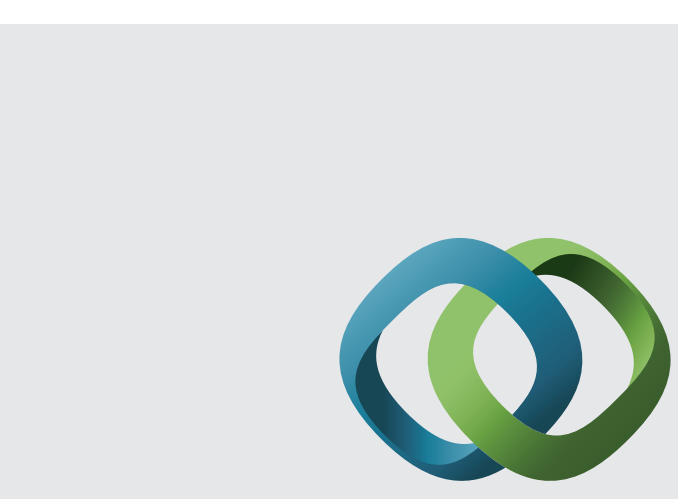

\section{Hindawi}

Submit your manuscripts at

http://www.hindawi.com
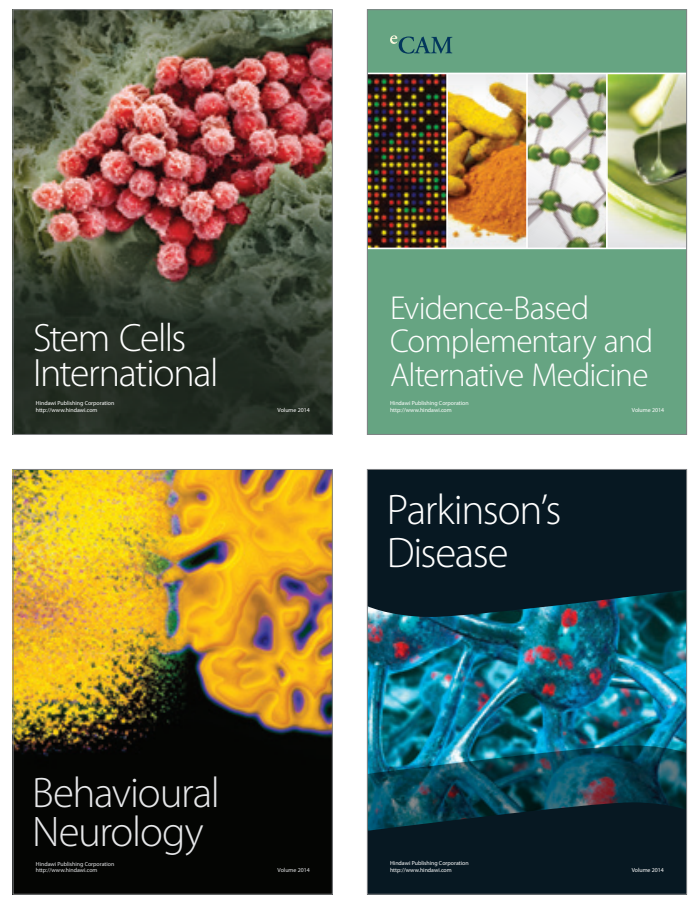
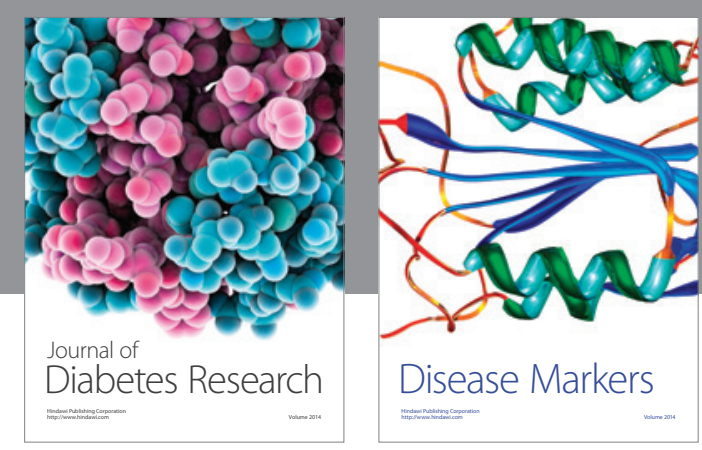

Disease Markers
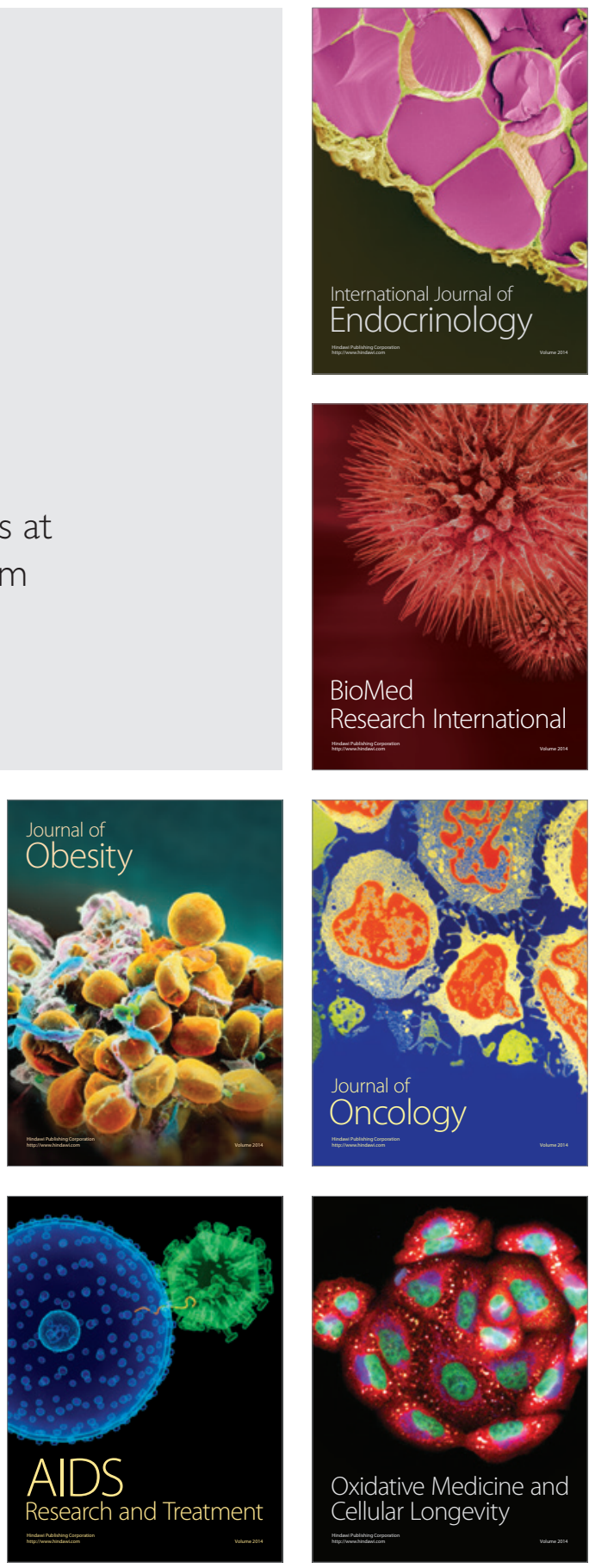